without explanation. On the credit side, the book is lavishly illustrated with photographs, but would benefit from more detailed site maps, and has only a short and selective bibliography at the end. For each individual site the author includes a section (sometimes quite lengthy) on the history of discovery and research, giving the names of the excavators, with their institutional affiliations and the dates of their investigations, but not the full bibliographical references that would carry the serious amateur forward to the next level of reading. This merely causes frustration, and was a serious error of judgement on the part of the author or publisher.

The introductory chapter contains much good general advice, on everything from camera equipment to car insurance, but is strongly slanted towards the North American reader. British tourists should check their own visa requirements and, with the collapse of the Mexican peso, should watch out for changes in currency regulations. Probably, too, El Salvador is a place to keep away from at the moment.

The emphasis throughout this book is on how to get to the sites and what to see there. The "ruin buff"' (a favourite phrase of the author) to whom this advice is directed comes over as rather timid and of a certain age, driving his - or more probably, her own car, worried about snakes, insects, sunburn and where to find the nearest cold drink, and in a perpetual dither about whether to wear boots or tennis shoes. Carrying a book of this size, too big and heavy to fit the pocket, walking is going to be hard work. Eye make-up tends to run, but if it rains you can always "carry a wig to wear when you get back to the cities or until you can get to a beauty shop". The main purpose of the visit is not to study aboriginal culture, but to get the best possible photos (or, at least, the same ones that everybody else takes) in the shortest possible time.

It's easy to poke fun, but this is a perfectly legitimate market to aim at. As a visit to any major ruin will demonstrate, there are a lot of people just like this (so many that they tend to get in the way of each others' photos), and they very often need precisely the kind of help that Joyce Kelly's book provides. So, too, do the more snobbish, those of us who through professional arrogance or sheer carelessness have got lost, gone hungry or arrived at a site to find the main buildings in deepest shadow. Thanks to Mrs Kelly, we should not make those mistakes again.

Warwick Bray is Reader in Latin American Archaeology at the Institute of Archaeology, University of London.

\section{Review supplements for 1983}

Dates of the five special review issues to be published by Nature in 1983 are: Textbooks, March 10th; Spring Books, April 28th; Journals, October 6th; Autumn Books, November 10th; and Christmas Books, December 1st.

\section{Wiggles put straight}

\section{Peter J. Smith}

Inside the Earth: Evidence from Earthquakes. By Bruce A. Bolt. Pp.191. Hbk ISBN 0-7167-1359-4; pbk ISBN 0-7167-1360-8. (W.H. Freeman: 1982.) Hbk \$22.50, £17.80; pbk \$11.95,£9.95.

PROFESSOR Bolt has dedicated his latest book not only to the pioneers of seismology in general but to Richard Dixon Oldham in particular, and with good reason. Though little remembered these days, it was Oldham who first showed, in 1906 , that earthquake waves could be used to demonstrate the existence in the Earth of major physical discontinuities and thus of a large distinct central core. Indeed, the reading of Oldham's paper on the subject to the Geological Society was a far more significant event for the Earth sciences than the now better-known San Francisco earthquake that was to follow just a few weeks later, for although the disaster in California undoubtedly gave both a scientific and a political boost to the study of seismology, it was Oldham who enabled such study at last to be "removed from the realm of speculation into that of knowledge".

The particular dedication is also appropriate in a quite different sense, even if Professor Bolt would not say so himself. Oldham's 1906 paper was a model of exposition; and in his own way and with far less tractable material Professor Bolt hardly achieves less. There are, for example, few things in seismology more difficult to explain to the non-specialist or undergraduate than terrestrial spectroscopy and few things more mind-boggling than trying to envisage the overtones of the spheroidal and toroidal eigenvibrations of the Earth. After reading Professor Bolt's 18-page chapter on these free oscillations, many may well feel that some of the minor mathematical and notational details elude them; but they will hardly come away with less than a very firm grasp of the physical principles involved. To be able to impart a strong sense of what is actually going on, as opposed to merely presenting some obscure mathematical description, is no mean achievement.

On the principle that anyone who can successfully explain the nature of the Earth's free oscillations can explain anything, it comes as no surprise to find that Professor Bolt maintains the same high standard of exposition in dealing with the rather less exotic, but no less interesting, aspects of seismology - the nature and measurement of earthquake waves, the significance of wave paths and travel times, the interpretation of seismograms in terms of broad Earth (and lunar and Martian) structure, the elucidation of finer (transition zone) structure, the estimation of density from seismic properties and so on.
An innovative approach to animal behaviour

NEW

Functional Ontogeny Explorations in the Functional Analysis of Behaviour

\section{Edited by}

David McFarland

Leading experts in the field of animal behaviour are concerned with developing a theoretical framework for a functional approach to the study of ontogeny.

Taking as a starting point the basic concepts in quantitative ethology, this book explores topics relevant to ontogeny. In particular, life history strategies and functional aspects of learning are discussed.

Contributors: Freeman, Houston, Kacelnik, McFarland, McNamara, Tovish.

1982/204 pages/Paperback ISBN $027308545 \mathrm{X} / \mathbf{£ 8 . 5 0}$

\section{Other recent titles}

from our Bioscience Programme include:

\section{Molecular Approaches} to Evolution

\section{Jacques Ninio}

This book explains aspects of molecular processes that are used by the cell in order to evolve. It provides a highly readable reflection on the genetic code and its origins.

1982/140 pages/Paperback ISBN $0273085212 / £ 5.95$

\section{Competition and} Coexistence of Species

A J Pontin

Competition and coexistence is a developing subject which has been inadequately covered in textbooks. This thorough review emphasises the experimental evidence for populations interacting in the field, and includes critical discussion of theoretical concepts.

1982/112 pages/Hardback ISBN 027308489 5/£8.95

For further details or a copy of our latest Bioscience Catalogue, please contact The Publicity Department, Pitman Books Ltd, 128 Long Acre.

London WC2E 9AN.

Telephone 01-379-7383. 